\title{
Evaluating the Trend and Extreme Values of Faecal Indicator Organisms in a Raw Water Source: A Potential Approach for Watershed Management and Optimizing Water Treatment Practice
}

\author{
Fasil Ejigu Eregno • Vegard Nilsen • Razak Seidu • \\ Arve Heistad
}

Received: 11 April 2014 / Accepted: 16 June 2014 / Published online: 10 July 2014

(C) Springer International Publishing Switzerland 2014

\begin{abstract}
This study demonstrates the use of microbial load time series, through trend and extreme event analysis, to evaluate the effectiveness of watershed management strategies and to understand the probabilistic behaviour of extreme events. Heterotrophic plate count (HPC), Clostridium perfringens, intestinal enterococci, Escherichia coli, and coliform bacteria, were monitored from 1999 to 2012 at Nedre Romerike Vannverk (NRV) drinking water treatment plant, which takes its source water from Glomma River, Norway. Mann-Kendall test, Seasonal Mann-Kendall test, and Sen's Slope Estimator were used for trend analysis over years and also seasonal trends were examined through linear regression. Mann-Kendall test results show a decreasing trend for all indicator microorganisms except Escherichia coli. Seasonal trend analysis results also indicate that Clostridium perfringens during autumn and intestinal enterococci during spring have a significantly decreasing trend. An increasing trend was observed for all pathogens during the summer season. Trend analysis results offer insights and crucial perspective for policy makers and planners to evaluate the existing watershed management strategies. Moreover, extreme microbial load events in the raw water was analysed using the POT method to estimate return levels of extreme indicator microbial load corresponding to selected return periods. It is of importance to calculate the return period of extreme microbial load events for the purpose of designing optimal pathogen barriers and performing risk analysis.
\end{abstract}

Keywords Trend analysis · Extreme event analysis · Indicator microbial load $\cdot$ Microbial water quality $\cdot$ Raw water quality

\section{Introduction}

Deterioration of the quality of water in a river system can significantly affect human health, the ecosystem and recreational activities. Increasingly complex management decisions require

F. E. Eregno $(\bowtie) \cdot$ V. Nilsen $\cdot$ R. Seidu $\cdot$ A. Heistad

Department of Mathematical Sciences and Technology, Faculty of Environmental Science and Technology, Norwegian University of Life Sciences, P.O. Box 5003, 1432 Ås, Norway

e-mail: efasilejigu@yahoo.com 
different water-quality data analyses that provide information for multiple purposes, including trend analyses to distinguish enhancement or worsening in water quality with time. Water quality trend analysis is necessary to determine if water quality has consistently improved, deteriorated, or remained constant over long time scales. Trend analysis also allows the detection of any significant change in water quality, which helps to enable the identification of potential causal mechanisms of such changes. Such assessments can highlight the effectiveness of environmental improvement strategies, reveal issues requiring attention, or uncover areas that need further research and evaluation (Reay 2009).

Increasing availability of reliable and long-term microbial water quality data in a drinking water treatment plant is potentially important for the statistical analysis of trends, extreme events, and degree of association with different physicochemical parameters. Trend can be tested for existence, extent and significance. The purpose of this paper is to apply statistical methods to assess changes in microbial water quality and to identify the magnitude of changes that would allow water management authorities to take adequate measures.

Statistical techniques can be used to analyse trends in biological and chemical water quality dataset. Such statistical methods can be usually categorized into parametric and nonparametric methods. Parametric methods are commonly underpinned by assumptions on data distribution and independence of the data. Non-parametric statistical methods are based on the ranks of the observations more willingly than the values themselves (Helsel and Hirsch 2002).

The physicochemical and environmental variables of water quality trend have been detected using Mann-Kendall test, seasonal Mann-kandell test, and regression analysis, in various studies, providing insight into ecological and environmental changes, as well as a basis for instituting a water resources safety strategy. Trend detection methods have not yet been applied on microbial water quality analysis, although there have been applications, for example, to promote pollutant monitoring and preservation of water resources at catchment scale (Luo et al. 2011), evaluate water quality of lakes (Yenilmez et al. 2011), get information on regulatory issues ( $\mathrm{Li}$ et al. 2010), and identify the dominant pollutant factors in water bodies (Yin and $\mathrm{Hu}$ 2009), among others. However, this study was conducted to detect the trends of microbial source water quality, which is quite different from other studies.

The other essential statistical analysis with regard to water quality is dealing with extreme events. The purpose of extreme value analysis is to quantify the stochastic behaviour of a process at strangely high or low levels. The stochastic behaviour of extreme events can be analysed by their probability distribution function. Estimating the probability of extreme events has become an important statistical discipline in applied science and is frequently used in environmental process modelling (Deoliveira 1988).

Many fields of modern science have to deal with events which are rare but have significant consequences. Extreme value theory is considered to provide the basis for the statistical modelling of such extremes. The potential of extreme value theory applied to meteorology, hydrology, insurance or finance, and water and air pollution has been recognized (Simiu and Heckert 1996; Freudenthal 1976; Konecny and Nachtnebel 1985; Jiang and Zhuang 2011; Huang and Batterman 2003; Kuchenhoff and Thamerus 1996; Ercelebi and Toros 2009; Ross 1987; Klugman 1997).

The proficient management of severe risks regarding the microbial concentration in the raw water requires an understanding of the probabilistic behaviour of extreme events. Frequency analysis of extreme load events can be used to obtain such understanding, and provide sufficient quantile estimates. The most widely used statistical methods of extreme value 
analysis are based on either block maxima or peak-over-threshold representation of extremes (Katz et al. 2002; Naess 1998). The Block Maxima (BM) statistical method considers maxima values in random intervals and the distribution of these maximum values converges to the Generalized Extreme Value (GEV) distribution. On the other hand, the Peak-Over-Threshold (POT) statistical method is based on the theorem that the distribution of random variables that exceed sufficiently high threshold value converges to the Generalized Pareto (GP) distribution (Ross 1987; Falk and Guillou 2008; Mazas and Hamm 2010a; Hosking and Wallis 1987). In recent studies, such methods are used to handle the probabilistic behaviour of extreme values of microbial water quality (Persson and La 2012; Hadas et al. 2004).

A Block maximum sample is constructed by extracting a series of maximum values of microbial load in each year, i.e., only one event per year is retained. On the other hand, the POT approach retains all peak values that exceed the threshold value. Thus, the POT approach is not restricted to only one event per year. The most important advantage of POT analysis is that it allows for a more coherent selection of extreme events to consider as a peak event, and provides the possibility to control the number of severe microbial load occurrences to be included in the analysis by appropriate selection of the threshold (Lang et al. 1999; Simiu and Heckert 1996). Due to the limited number of observation years and the above mentioned advantages, we selected here to apply the POT analysis.

In this study, four different kinds of statistical trend analysis were used to identify significant changes in the microbial load time series of the drinking water source. These are the following: (1) Mann-Kendall Test: a non-parametric trend analysis that compares the change in the dataset ranks over time; (2) Sen's slope estimate: a non-parametric estimate of the change in the variable over time by calculating the slope; (3) Seasonal Kendall Test: a nonparametric method that first groups the data by month of the year, and then the Mann-Kendall test is performed on each group of monthly data; and (4) Linear Regression: a parametric trend analysis that computes the slope of the observations over time using ordinary least squares regression. The paper provides information about the trend of changes, magnitude and frequency of extreme microbial load in the Glomma River at Nedre Romerike Vannverk (NRV) drinking water treatment plant in Norway. Knowledge of such information is essential to evaluate the catchment management strategies to abate microbial pollution and also to develop safety plans in drinking water treatment plants.

\section{Study Area and Detaset}

\subsection{Study Area}

This study was based on raw water quality data from NRV drinking water treatment plant located at $59^{\circ} 57^{\prime} 18.9$ "latitude and $11^{\circ} 1^{\prime} 29^{\prime \prime}$ longitude in Norway. NRV draws raw water from river Glomma, the largest river in Norway, with a catchment area of $41,200 \mathrm{~km}^{2}$ (13\% of the total area of the country). The northwestern part of the river's watershed is dominated by high mountains, while the eastern part is covered by forest. The central and southern parts of the watershed are covered by large agricultural areas, which constitute $5.8 \%$ of the total catchment area. The Glomma river basin contains Lake Mjøsa, the largest lake in Norway, with a surface area of $350 \mathrm{~km}^{2}$. The average annual flow of the river at Solbergfoss (the lower-most reservoir) is $700 \mathrm{~m}^{3} / \mathrm{s}$. The discharge usually varies from $150 \mathrm{~m}^{3} / \mathrm{s}$ to $3500 \mathrm{~m}^{3} / \mathrm{s}$ during the year. Approximately 675,000 inhabitants live in the catchment area (Grizzetti et al. 2007). 


\subsection{Data}

Data used for the analysis were extracted from secondary raw water quality data on indicator organisms from 1999 to 2013. This study used weekly records of five indicator microorganisms in the NRV raw water source namely, Heterotrophic plate count (HPC), Clostridium perfringens (C.perfringens), intestinal enterococci, Escherichia coli (E.coli), and coliform bacteria. The physico-chemical parameters were river discharge, temperature, $\mathrm{pH}$, electrical conductivity, turbidity, and colour. For E.coli and coliform bacteria, weekly records were available from 1999 to 2013, for intestinal enterococci from 2002 to 2013, and for HPC and C.perfringens from 2005 to 2013. However, some records were missing and, during analysis, the missing values were treated as such (not filled with mean or neighbourhood values). In this study, Principal Components Analysis (PCA), Trend analysis, POT analysis and their graphical presentations were performed in Addinsoft's XLSTAT 2012 and R statistical software (Heffernan 2012; XLSTAT 2012).

\section{Statistical Analysis}

The main statistical analyses undertaken in this study were Principal Components Analysis (PCA), Trend analysis and extreme event analysis (POT analysis).

\subsection{Descriptive and Principal Components Analysis}

Descriptive statistics is useful for exploring and examining the basic features of the data prior to applying statistical tests. The descriptive statistics of the physicochemical, as well as the microbial load detaset, was carried out to explore the feature of the detaset.

Principal Components Analysis (PCA) is a multivariate statistical method that reduces the dimensionality of the detaset by performing a covariance analysis between factors, and this reduction is achieved by transforming the detaset into a new set of variables called the principal components (Hait and Schektman 1980). In this study, PCA was performed to identify the most important physicochemical factors that affect the microbial quality of raw water source. For the purpose of this study, the physicochemical parameters and indicator microbial data were subjected to the analysis. PCA analysis was performed using XLSTAT 2012 software.

\subsection{Trend Analysis}

\subsubsection{Mann-Kendall Test}

The Mann-Kendall trend test is a non-parametric statistical analysis used for identifying trends in time series data. The statistical analysis contrasts the relative magnitudes of data points rather than the data values themselves. The result of the test is not decided by the magnitude of the data points but by the ranking of individual data points (Gilbert 1987). The fundamental principle of Mann-Kendall test is to investigate the signs of all pairwise differences of the data values, ranked in chronological order. The benefit of this statistical analysis is that the data do not need to coincide with any particular distribution. Both the Kendall tau coefficient $(\tau)$ and Mann-Kendall coefficient (S) are used to identify rank correlation. Kendall $\tau$ is defined as the actual rating score of correlation divided by the maximum probable score. To find the rating 
score for a time series, the detaset is sorted in ascending order according to time (Hirsch et al. 1982; Antonopoulos et al. 2001). The test statistics S is defined as:

$$
\mathrm{S}=\sum_{\mathrm{i}=1}^{\mathrm{n}-1} \sum_{\mathrm{j}=\mathrm{i}+1}^{\mathrm{n}} \operatorname{sign}\left(\mathrm{x}_{\mathrm{j}}-\mathrm{x}_{\mathrm{i}}\right)
$$

where $\mathrm{S}$ is the rating score (Mann-Kendall sum); $x$ is the observation value; $\mathrm{n}$ is the number of observation values in the series; $i$ and $\mathrm{j}$ are counters; sign is a function having values of $-1,0$, or +1 if $\left(x_{i}-x_{j}\right)$ is negative, zero, or positive, respectively. The Kendall $\tau$ is calculated as:

$$
\tau=\frac{\mathrm{S}}{\mathrm{S}_{\max }}
$$

where the maximum value of $\mathrm{S}$ is calculated as:

$$
\mathrm{S}_{\max }=0.5 \mathrm{n}(\mathrm{n}-1)
$$

A negative value of $\mathrm{S}$ or $\tau$ is a sign of a decreasing trend, and a positive value indicates an increasing trend. However, it is essential to compute the probability connected with $\mathrm{S}$ or $\tau$ and the sample size, $n$, to calculate the statistical significance of the trend. In the case where there is no trend in either ranking, the distribution of $\mathrm{S}$ can be well approximated by a normal distribution with mean zero and variance calculated as:

$$
\operatorname{Var}(\mathrm{S})=\frac{\mathrm{n}(\mathrm{n}-1)(2 \mathrm{n}+5)-\sum_{\mathrm{i}=1}^{\mathrm{m}} \mathrm{t}_{\mathrm{i}}(\mathrm{i})(\mathrm{i}-1)(2 \mathrm{i}+5)}{18}
$$

provided that $n \geq 10$ and $t_{i}$ is the number of ties up to sample $i$. Then, the normal distribution parameter (the Mann-Kendall statistic, $Z$ ) is calculated as:

$$
\mathrm{Z}=\left\{\begin{aligned}
\frac{1}{\sqrt{\operatorname{Var}(\mathrm{S})}}(\mathrm{S}-1) & \text { if } \mathrm{S}>0 \\
0 & \text { if } \mathrm{S}=0 \\
\frac{1}{\sqrt{\operatorname{Var}(\mathrm{S})}}(\mathrm{S}+1) & \text { if } \mathrm{S}<0
\end{aligned}\right.
$$

The Mann-Kendall statistic, $Z$, at this point follows a normal distribution. A negative (positive) value of $Z$ signifies a downward (upward) trend. Significance levels $\alpha$ are applied for testing either an increasing or decreasing monotone trend. If $Z$ values appear greater than $Z_{\alpha / 2}$, where $\alpha$ shows the significance level, then the trend is considered as significant.

\subsubsection{Seasonal Mann-Kendall Test}

The seasonal Mann-Kendall Test is a modified version of Mann-Kendall test that accounts for seasonality by computing the Mann-Kendall test on each of $m$ seasons independently, in order to identify seasonal trend. Monthly scores are then added to get the test statistic. By adding the variances of the Kendall score statistic for each month, the variance of the test statistic is obtained. The normal approximation can be used to evaluate significance level. It carries all the robust statistical properties offered by the Mann-Kendall test. The Seasonal Mann-Kendall test is established on the basis that the trend is cyclically varying in relation to the seasons of the year. It is used to analyse time series data for the possible existence of an upward or downward 
trend, at a particular significance level, while accounting for the effect of seasonality (Hirsch et al. 1982; Yu et al. 1993). Kendall's $\mathrm{S}$ statistics $\mathrm{S}_{\mathrm{i}}$ for each season are added to form the overall statistic S:

$$
\mathrm{S}=\sum_{\mathrm{i}=1}^{\mathrm{m}} \mathrm{S}_{\mathrm{i}}
$$

\subsubsection{Sen's Slope Estimator}

Sen's slope statistical trend analysis is a non-parametric procedure. Its statistic is computing the median slope of each point-pair slope in the detaset. To obtain an estimate of the slope Q, the slopes of all pairs in the detaset are calculated for each time period by the equation (Sen 1968):

$$
\mathrm{Q}=\frac{\mathrm{x}_{\mathrm{j}}-\mathrm{x}_{\mathrm{k}}}{\mathrm{j}-\mathrm{k}}
$$

where $\mathrm{Q}$ is the slope between data points $\mathrm{k}$ and $\mathrm{j}, \mathrm{x}_{\mathrm{k}}$ is the data measurement at time $\mathrm{k}, \mathrm{x}_{\mathrm{j}}$ is data measurement at time $\mathrm{j}, \mathrm{j}$ is the time after time $\mathrm{k}$. If there are $n$ values $x_{j}$ in the time series data, we get as many as $N=n(n-1) / 2$ slope estimates $Q$. Its sign reflects the trend direction, while its value reflects how steep the trend is. Sen's slope estimator is then calculated by choosing the middle-ranked slope as follows;

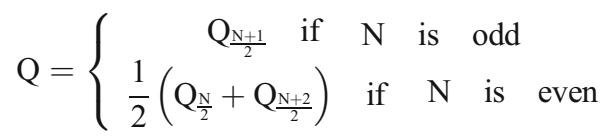

where $\mathrm{N}$ is the number of calculated slopes.

\subsubsection{Linear Regression Test}

Linear regression is the most popular parametric statistical method to identify a monotonic trend in a time series detaset. Let $y_{i}$ denote the response variable observed at time, $t_{i}$. A conventional linear regression model for trend analysis is given by:

$$
y_{i}=b_{0}+b_{1} t_{i}+e_{i}
$$

The parameter $b_{1}$ in a linear regression model expresses the rate of change of $\mathrm{y}_{\mathrm{i}}$ in time. The slope coefficient $\left(b_{1}\right)$ is statistically tested under the null hypothesis that it is equal to zero. The $\mathrm{t}$-statistic on $b_{1}$ is tested to decide if it is significantly different from 0 . If the slope is non-zero (upward or downward slope), the null hypothesis of zero slopes over time is rejected, and one can conclude that there exist a linear trend in y over time. Besides of providing a measure of significance based on the hypothesis test on the slope, it also gives the magnitude of the rate of change (Abaurrea et al. 2011).

\subsubsection{Test Statistics}

All the statistical tests were based on testing the null hypothesis. The null hypothesis $\left(\mathrm{H}_{\mathrm{o}}\right)$ is that no change has occurred in microbial concentration of a variable over time, or that no trend is present. The alternative hypothesis $\left(\mathrm{H}_{1}\right)$ is that a change has occurred over time, or that an increasing or decreasing trend in the concentration of a variable is evident. The statistical tests 
determine the probability ( $p$-value) of the statistics and the slope of the trend line. The smaller the $p$-value is, the greater the weight of evidence against $\mathrm{H}_{\mathrm{o}}$. A significance level $\alpha=0.05$ corresponds to $95 \%$ confidence level.

\subsection{Extreme Event Analysis}

\subsubsection{Peak-Over-Threshold Method and Generalized Pareto Distribution}

Extreme Value Theory is used to model the tail return levels and then incorporate this into risk assessment. Two main approaches are proposed in the literature: Block maximum and PeakOver-Threshold method (Kasperski and Hoxey 2008; Katz et al. 2002; Deoliveira 1988). The Block Maximum picks the highest value per year and does not include all extreme values because any second highest would be dropped out of the sample. The POT method considers all values exceeding a certain predefined threshold. In this study, we apply the POT method based on the GP distribution to describe tail behaviour that enables us to estimate the extreme quantiles.

If an unidentified distribution function $\mathrm{F}$ of a random variable $\mathrm{X}$ over a high threshold value $\mathrm{u}$ is considered, the cumulative distribution function $\mathrm{F}_{\mathrm{u}}(\mathrm{y})$ of exceedances of $\mathrm{X}$ above a high threshold value is defined as (Embrechts et al. 1997):

$$
\mathrm{F}_{\mathrm{u}}(\mathrm{y})=\operatorname{Pr}(\mathrm{X}-\mathrm{u} \leq \mathrm{y} \mid \mathrm{X}>\mathrm{u})=\frac{\mathrm{F}(\mathrm{x})-\mathrm{F}(\mathrm{u})}{1-\mathrm{F}(\mathrm{u})}, \quad 0 \leq \mathrm{y} \leq \mathrm{x}_{\mathrm{F}}-\mathrm{u}
$$

where $\mathrm{X}$ is a random variable, $\mathrm{u}$ is a given threshold, $\mathrm{y}=\mathrm{x}-\mathrm{u}$ are the excesses, and $\mathrm{x}_{\mathrm{F}}$ is the right end point of $F$. As the threshold value $u$ gets large, the Extreme Value Theory provides us with the underlying distribution of $\mathrm{F}_{\mathrm{u}}(\mathrm{y})$, i.e., the distribution of the excess $\mathrm{F}_{\mathrm{u}}(\mathrm{y})$ approximated by $\mathrm{F}(\mathrm{y}, \mathrm{k}, \alpha)$ (Iii 1975):

$$
\mathrm{F}_{\mathrm{u}}(\mathrm{y}) \approx \mathrm{F}(\mathrm{y}, \mathrm{k}, \alpha), \quad \mathrm{u} \rightarrow \infty
$$

where:

$$
\mathrm{F}(\mathrm{y}, \mathrm{k}, \alpha)= \begin{cases}1-\left(1-\mathrm{k} \frac{\mathrm{y}}{\alpha}\right)^{1 / \mathrm{k}}, & \mathrm{k} \neq 0 \\ 1-\exp \left(-\frac{\mathrm{y}}{\alpha}\right), & \mathrm{k}=0\end{cases}
$$

where $\alpha$ and $k$ are scale and shape parameters, $\mathrm{x}>0$ for $\mathrm{k} \leq 0$, and $\mathrm{x} \in[0, \alpha / \mathrm{k}]$ for $\mathrm{k}>0$. This expression is the same as the GP distribution (Castillo and Hadi 1997).

\subsubsection{Threshold Selection}

The values of extreme quantile estimation greatly depend on the choice of the threshold. The selection of the threshold value is a trade-off between variance and bias. A high threshold value would produce a reduced amount of excesses used to formulate the model, leading to large variance. A low threshold value would lead to a violation of the asymptotic foundation of the model, leading to bias (Klugman 1997; Ross 1987). The right position is the lowest possible threshold for which the excesses follow the GP distribution. Two methods are available for this: A simple graphical method that plots the estimated shape parameter $k$ as function of threshold. When the threshold is high enough, the shape parameter should be approximately independent of threshold. The graphs are plotted focusing on the extreme 
values where the threshold value is expected. The second method is the plot of mean excesses as a function of threshold. The mean excess function describes the expected overshoot of a threshold given that exceedances occur. The interpretation of the plot is explained by various authors (Klugman 1997; Mazas and Hamm 2010b; Wong and Li 2010). In these studies, it is stated that if the observed plot follows a rationally straight line with positive gradient over a distinct value of $\mathrm{u}$, then this is a sign that the excesses over this threshold follow a GP distribution with positive shape parameter. This property was used as a criterion for the selection of threshold in this study (Leadbetter and Rootzen 1988).

\subsubsection{Return levels (quantile)}

The return level $X_{T}$ is defined as the probability $p$ that $X_{T}$ is exceeded in any given year or the level that is likely to be exceeded on the average once every $1 / p$ year. In extreme value statistics terminology, $X_{T}$ is the return level related to the return period T=1/p (Katz et al. 2002). From the GP distribution, the return level is derived by setting the cumulative distribution function equal to the anticipated quintile, $(1-\mathrm{p})$, and then solving for the return level (El-Aroui and Diebolt 2002). Suppose that the GP distribution is an appropriate model for $y$, the $N$ period return level is denoted as follows:

$$
X_{T}=\frac{\alpha}{k}\left\{1-\left\{\frac{-\log \left(1-\frac{1}{T}\right)}{\lambda}\right\}^{k}\right\}+u
$$

where $X_{T}$ is the return level, $T$ is the return period; $\lambda$ is the number of exceedances per year.

\subsubsection{Model Validation}

Graphical model validation is a vital step in the model building process, since it allows the investigator to have confidence in the inference obtained. We use two methods of validation for assessing the quality of a fitted GP distribution model; these are probability plots and quantile plots. A GP distribution model fits the data well, if a probability plot and a quantile plot of the model and data points could be approximated by a straight line (Katz et al. 2002).

\section{Result and Discussion}

\subsection{Descriptive Statistics of Water Quality Parameters}

The summary of descriptive statistics of the water quality variables, based on the weekly data from 2008 to 2012, is presented in Table 1. Among the physicochemical variables, the highest observation ranges were observed in river discharge $\left(2314.8 \mathrm{~m}^{3} / \mathrm{s}\right)$, while the lowest were observed in $\mathrm{pH}$ (1.7). Among indicator microbial load detaset, HPC recorded the highest median value of $365 / \mathrm{mL}$ while C.perfringens load in the source water exhibited the least median value of $5 / 100 \mathrm{~mL}$. The standard deviation around the means is substantially high in HPC, coliform bacteria, E.coli and intestinal enterococci with values 1920.4, 291.7, 47.5, and 23.5 , respectively. This could be a result of complex land use in the catchment area and seasonal variation of different anthropogenic and physicochemical factors surrounding the study area.

The numerical values of the correlation coefficient, $r$, for physicochemical water quality parameters and indicator microbial load records during the period of five years (from 2008 to 2012) are tabulated in Table 2. A highly positive correlation is observed between $\mathrm{pH}$ and 


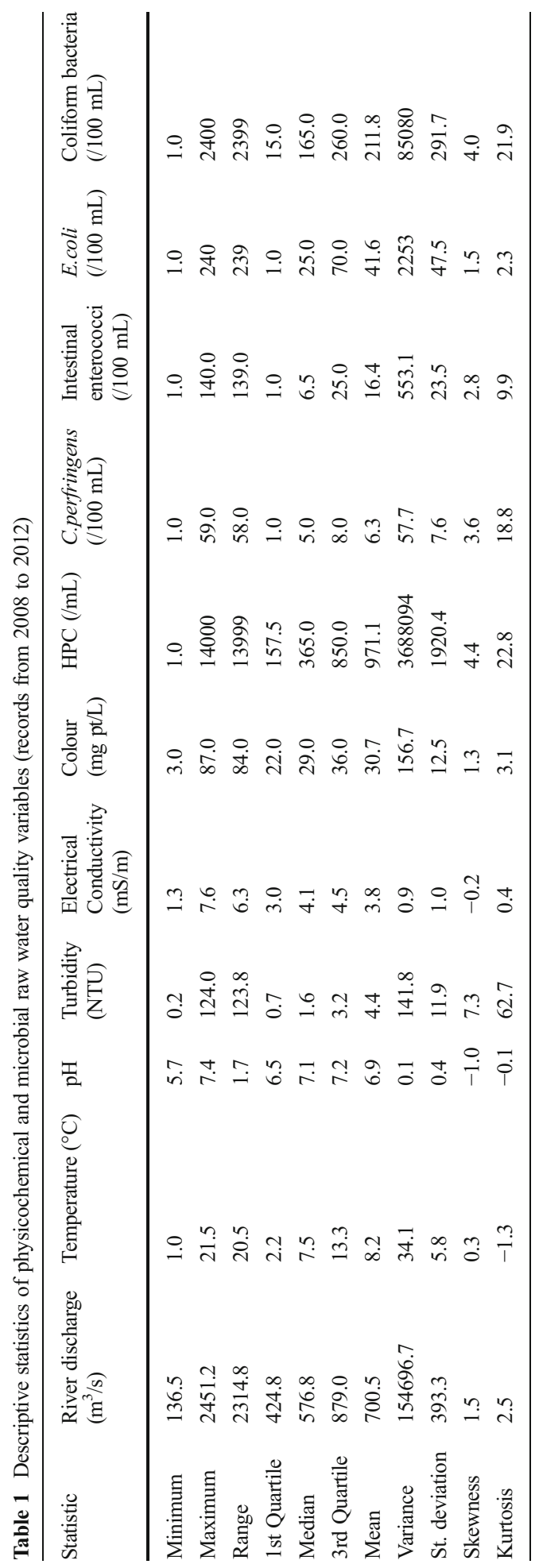




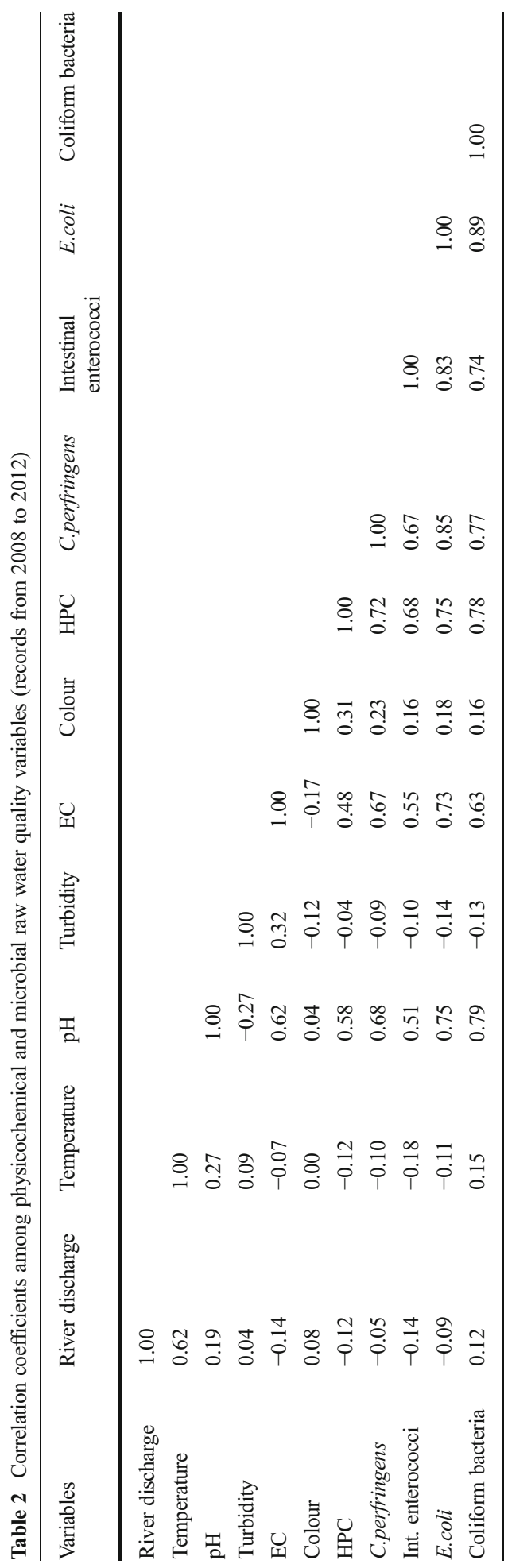


indicator microorganism load (from $\mathrm{r}=0.51$ to $\mathrm{r}=0.79$ ), and $\mathrm{EC}$ and indicator microorganism load (from $r=0.48$ to $r=0.73$ ), while a very weak negative correlation was observed between turbidity and indicator microorganism load (from $\mathrm{r}=-0.04$ to $\mathrm{r}=-0.14$ ).

\subsection{Principal Component Analysis}

Principal Component Analysis (PCA) was carried out to identify the most important physicochemical factors that affect the microbial quality of source water. When five source water microbial load records and six physicochemical variables were reduced to four principal components with eigenvalue greater than one, the identified four components accounted for around $86 \%$ of the variance in the detaset. Table 3 presents rotation factor correlation coefficients of original water quality parameters. Based on the first of the four principal components, Factor 1 (F1), the coefficients of $\mathrm{pH}$ and $\mathrm{EC}$ are relatively notable, and F1 can be classified as a mineral related water quality factor. In Factor 2 (F2), the coefficients of river discharge and temperature are remarkable, and this factor can be classified as weather related factor. In Factor 3 (F3), the coefficients of turbidity and colour are significant and F3 can be classified as organic matter related factor. Finally, Factor 4 (F4) is almost the same as factor 3. Figure 1 shows the PCA biplot obtained from the first two principal components, accounting for $64.3 \%$ of the variance in the detaset. It can be seen that $\mathrm{pH}, \mathrm{EC}$, turbidity and colour are more correlated with microbial water quality parameters, and river discharge and temperature are weakly correlated with microbial water quality parameters, but highly correlated to each other.

\subsection{Trend analysis}

In order to visualize the annual fluctuation of each indicator microbial load records, annual mean values \pm standard deviations are plotted in Fig. 2. As one can see from Fig. 2, the annual fluctuation in 2002 and 2003 for intestinal enterococci, E.coli, and coliform bacteria, in 2009

Table 3 Rotation factor correlation coefficients for physicochemical and microbial raw water quality parameters (records from 2008 to 2012)

\begin{tabular}{|c|c|c|c|c|}
\hline Variables & $\mathrm{F} 1$ & $\mathrm{~F} 2$ & F3 & $\mathrm{F} 4$ \\
\hline River discharge & 0.007 & 0.881 & 0.013 & 0.043 \\
\hline Temperature & 0.012 & 0.895 & 0.153 & -0.047 \\
\hline $\mathrm{pH}$ & 0.815 & 0.280 & 0.002 & -0.353 \\
\hline Turbidity & -0.092 & 0.006 & 0.778 & 0.609 \\
\hline $\mathrm{EC}$ & 0.750 & -0.174 & 0.546 & -0.036 \\
\hline Colour & 0.197 & 0.111 & -0.651 & 0.656 \\
\hline $\mathrm{HPC}$ & 0.835 & 0.144 & -0.059 & 0.290 \\
\hline C.perfringens & 0.894 & -0.093 & -0.047 & 0.054 \\
\hline Intestinal enterococci & 0.826 & -0.226 & -0.074 & 0.054 \\
\hline E.coli & 0.965 & -0.130 & -0.039 & -0.037 \\
\hline Coliform bacteria & 0.933 & 0.149 & -0.024 & -0.061 \\
\hline Eigenvalue & 5.256 & 1.817 & 1.364 & 1.026 \\
\hline Variability (\%) & 47.778 & 16.522 & 12.398 & 9.328 \\
\hline Cumulative $\%$ & 47.778 & 64.300 & 76.698 & 86.026 \\
\hline
\end{tabular}




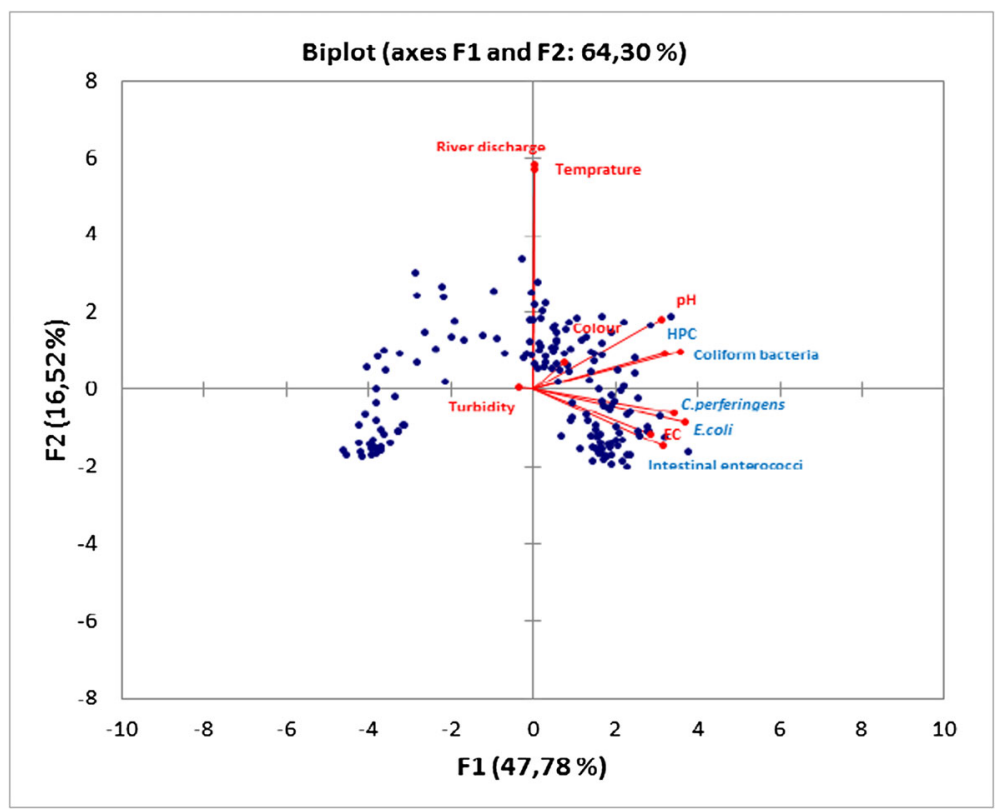

Fig. 1 PCA biplot of physicochemical and microbial water quality variables

and 2011 for C.perfringens, and in 2009 for HPC was relatively high. As we can see from the monthly average microbial load in the raw water (Fig. 3), the trend in microbial load was characterized by strong seasonal fluctuations with low load during the summer season (June, July, and August) for all indicator microorganisms; this indicates that microbial concentration per unit volume of water is reduced due to the summer flood dilution effect.

\subsubsection{Mean monthly microbial load in the raw water}

To present the monthly mean value fluctuation of each indicator microbial load records, by taking year 2012 as a representative year, monthly mean values \pm standard deviations are plotted in Fig. 4. It is shown that the monthly mean value fluctuation for the representative year, 2012 was high, and it is relatively very high during March and July for all indicator microbial load records. Both high monthly and annual mean value fluctuation indicates that non-parametric trend tests are likely to be more powerful than parametric techniques in this study.

Statistical results from trend analysis are given in Table 4. Based on the Mann-Kendall test, the Null Hypothesis of no trend was rejected for only C.perfringens. In other words, statistically significant trend was observed for C.perfringens $(p<0.006)$. The Mann-Kendall test Statistic (S), revealed conformity in the magnitude of the statistic, which indicates that there was a decreasing trend for all indicator microbial organisms except E.coli. The decreasing trend of Sen's Slope Estimator, except for E.coli, also supports the Mann-Kendall test result. The Seasonal Mann-Kendall test is applied in order to test whether the trend is cyclical, varying with the seasons in the year or not. In all microbial load cases, there was not any statistically significant trend. However, the magnitude varied, showing a decreasing trend in the case of HPC, C.perfringens, close to zero in the case of intestinal enterococci and coliform bacteria, and increasing in the case of E.coli. 

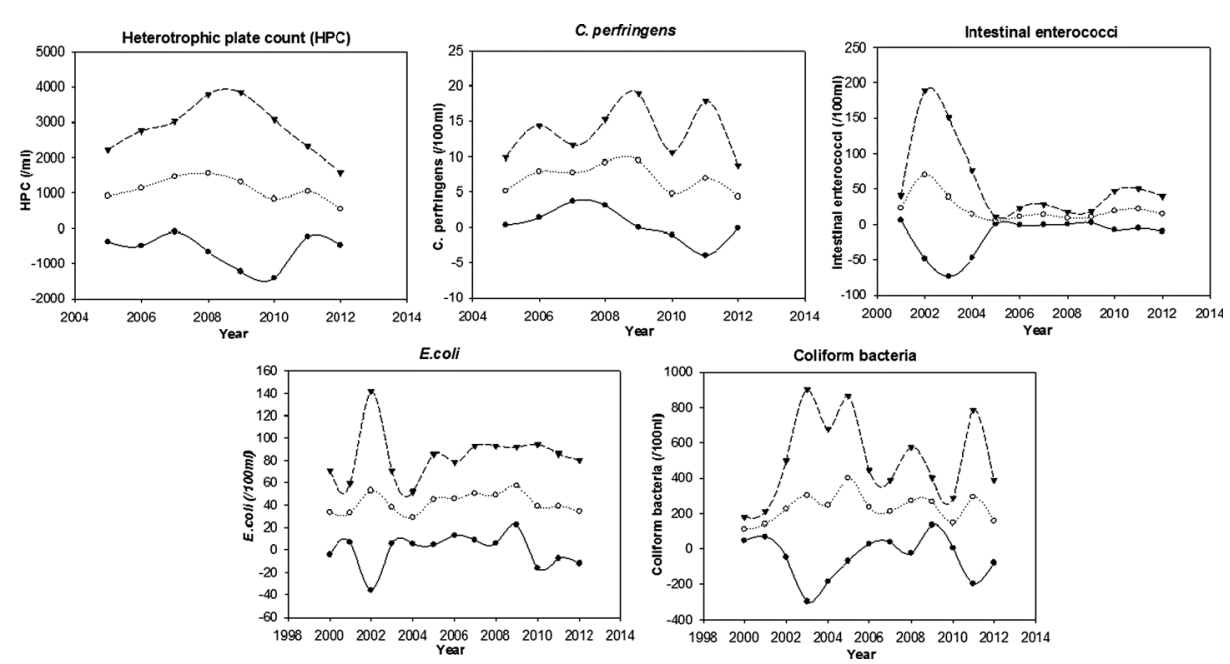

Fig. 2 The fluctuation of annual mean values of source water microbial load (annual mean value \pm STDEV)

The downward trend of the indicator microbial organisms in the trend analysis indicates an improvement in microbial water quality. This observed trend may be attributed to improvements in wastewater treatment and watershed management within the Glomma basin. Even though the upward trend in E.coli load in the raw water is not statistically significant ( $p>0.913$ ), there is a need for strategies to be implemented to reduce the trend.

\subsubsection{Monthly maximum microbial load in the raw water}

Trend analysis of monthly maximum microbial load was carried out in order to investigate only trend in extreme events. Figure 5 presents the monthly maximum microbial load for each indicator microorganism. The Mann-Kendall trend test results for monthly maximum microbial load indicates an evidence of a rising trend for intestinal enterococci, E.coli, and coliform bacteria,

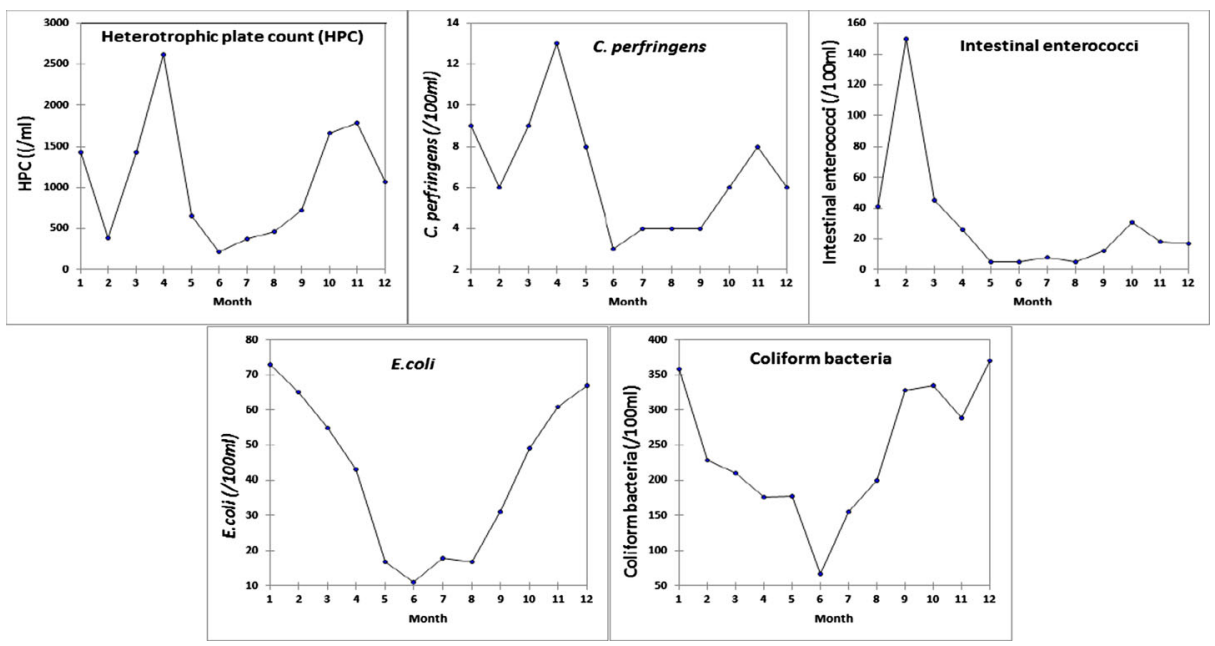

Fig. 3 Monthly average indicator microbial load in the raw water 

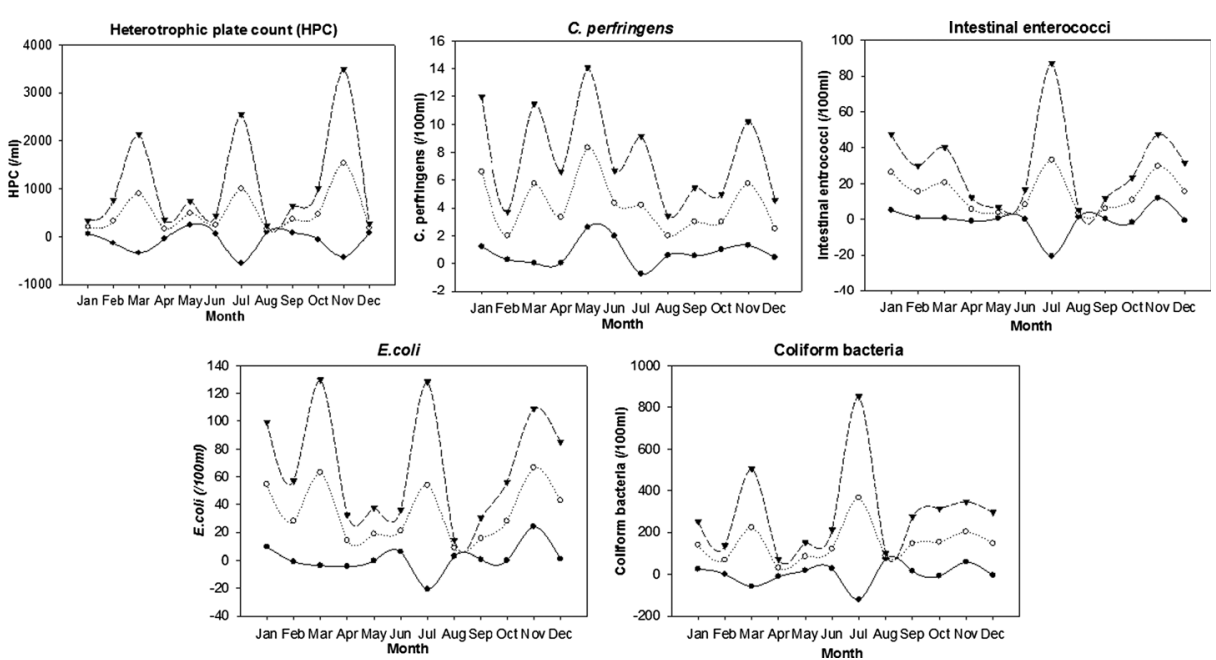

Fig. 4 The fluctuation of mean monthly values of source water microbial load (monthly mean value \pm STDEV) for year 2012

and a negative trend for HPC and C.perfringens. However, there was no statistical significance $(p>0.415)$ for any of the microbial organisms (Table 5).

The Sen's slope test for HPC showed a decreasing slope, while for E.coli and coliform bacteria an increasing slope. However, there was no change in the slope for C.perfringens and intestinal enterococci. The result of the Mann-Kendall test and Sen's slope trend analysis have revealed that the extreme values of E.coli and coliform bacteria have an increasing trend even though there was no statistical significance.

Table 4 Mann-Kendall, Sen's slope and Seasonal Mann-Kendall trend test for monthly mean value of microbial load in raw water

\begin{tabular}{|c|c|c|c|c|c|}
\hline Mann-Kendall test & $\mathrm{HPC}$ & $\begin{array}{l}\text { Clostridium } \\
\text { perfringens }\end{array}$ & $\begin{array}{l}\text { Intestinal } \\
\text { enterococci }\end{array}$ & $\begin{array}{l}\text { Escherichia } \\
\text { coli }\end{array}$ & $\begin{array}{l}\text { Coliform } \\
\text { bacteria }\end{array}$ \\
\hline Kendall tau & -0.135 & -0.195 & -0.015 & 0.006 & -0.041 \\
\hline $\mathrm{S}$ & -577 & -830 & -129 & 69 & -463 \\
\hline $\operatorname{Var}(\mathrm{S})$ & 90785 & 90704 & 264238 & 386275 & 386302 \\
\hline$p$-value (two tailed) & 0.056 & 0.006 & 0.803 & 0.913 & 0.457 \\
\hline alpha & 0.05 & 0.05 & 0.05 & 0.05 & 0.05 \\
\hline Conclusion & Decreasing & Sign. decreasing & Decreasing & Increasing & Decreasing \\
\hline Sen's slope & -3.48 & -0.041 & -0.004 & 0.006 & -0.147 \\
\hline \multicolumn{6}{|l|}{ Seasonal Mann-Kendall } \\
\hline Kendall tau & -0.143 & -0.175 & 0.011 & 0.034 & 0.005 \\
\hline $\mathrm{S}^{\prime}$ & -36 & -44 & 6 & 27 & 4 \\
\hline$p$-value (two tailed) & 0.129 & 0.062 & 0.943 & 0.607 & 0.953 \\
\hline alpha & 0.05 & 0.05 & 0.05 & 0.05 & 0.05 \\
\hline Conclusion & Decreasing & Decreasing & Increasing & Increasing & Increasing \\
\hline
\end{tabular}




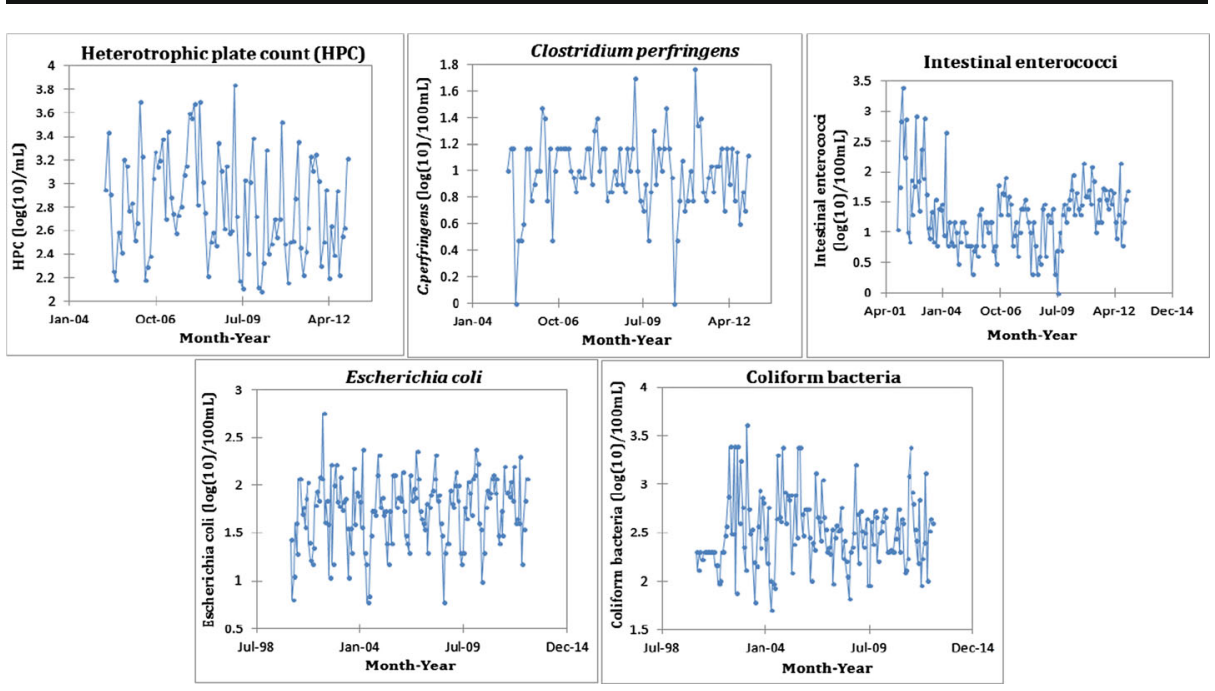

Fig. 5 Time series plot of monthly maximum indicator microbial load in the raw water

A Seasonal Kendall test was carried out in this study to test whether the extreme microbial load trends are affected by seasonal changes. The results of the Seasonal Kendall test on the microbial organisms showed no statistically significant trend. There was evidence of a rising trend for intestinal enterococci, E.coli and coliform bacteria, and a decreasing trend for HPC. There was no change in trend of C.perfringens.

Table 5 Mann-Kendall, Sen's slope, and Seasonal Mann-Kendall trend test for monthly maximum value of microbial load in raw water

\begin{tabular}{|c|c|c|c|c|c|}
\hline Mann-Kendall test & HPC & $\begin{array}{l}\text { Clostridium } \\
\text { perfringens }\end{array}$ & $\begin{array}{l}\text { Intestinal } \\
\text { enterococci }\end{array}$ & $\begin{array}{l}\text { Escherichia } \\
\text { coli }\end{array}$ & $\begin{array}{l}\text { Coliform } \\
\text { bacteria }\end{array}$ \\
\hline Kendall tau & -0.051 & -0.06 & 0.038 & 0.097 & 0.042 \\
\hline $\mathrm{S}$ & -218 & -244 & 329 & 1088 & 469 \\
\hline $\operatorname{Var}(\mathrm{S})$ & 90740 & 88887 & 263011 & 385904 & 385485 \\
\hline$p$-value (two tailed) & 0.471 & 0.415 & 0.522 & 0.80 & 0.451 \\
\hline alpha & 0.05 & 0.05 & 0.05 & 0.05 & 0.05 \\
\hline Conclusion & Decreasing & Decreasing & Increasing & Increasing & Increasing \\
\hline Sen's slope & -2.679 & 0 & 0 & 0.136 & 0.202 \\
\hline \multicolumn{6}{|l|}{ Seasonal Mann Kendall } \\
\hline Kendall tau & -0.068 & 0.004 & 0.050 & 0.128 & 0.054 \\
\hline $\mathrm{S}^{\prime}$ & -17 & 0.00 & 32 & 99 & 42 \\
\hline$p$-value (two tailed) & 0.487 & 1.00 & 0.482 & 0.051 & 0.415 \\
\hline alpha & 0.05 & 0.05 & 0.05 & 0.05 & 0.05 \\
\hline Conclusion & Decreasing & No trend & Increasing & Increasing & Increasing \\
\hline
\end{tabular}




\subsubsection{Seasonal trend analysis of microbial load in the raw water}

According to the Norwegian Meteorological Institute, the four seasons are defined as four equal-length periods of 3 months in the region and this study adopts the same period: winter (December-February), spring (March-May), summer (June-August), and autumn (SeptemberNovember).

Seasonal trends in data were examined through linear regression analysis. The trend was determined by calculating a linear regression line using the least squares fit method. The slope of the linear regression line in this study is used to evaluate a trend direction of the mean microbial load for each season and the statistical summary of the linear regression analysis is presented in Table 6. The regression result revealed a positive trend for all indicator microorganisms during the summer season (June-August). However, this relationship was not statistically significant $(p>0.215)$. During winter, spring and autumn seasons, the microbial load showed a decreasing trend. The results also show that for C.perfringens during autumn (September-November) and for intestinal enterococci during spring (March-May), the raw water microbial load is significantly decreased $(p<0.016)$. The possible reasons for the increasing trend for microbial concentration during the summer season could be the intensification of anthropogenic activities and also the alteration of precipitation patterns during the summer time. The speculated anthropogenic summer activities may include different outdoor recreational and on farm activities. Therefore, attention should be given to reverse the situation.

Table 6 Linear regression statistical trend tests for seasonal microbial load in raw water

\begin{tabular}{|c|c|c|c|c|c|c|c|}
\hline Microbial pathogen & Season & Slope $\left(b_{1}\right)$ & Standard error & $\mathrm{t}$ & $\operatorname{Pr}>|t|$ & $\alpha$ & Trend \\
\hline \multirow[t]{4}{*}{ HPC } & winter & -237.146 & 208.2 & -1.139 & 0.306 & 0.05 & Decreasing \\
\hline & Spring & -255.415 & 103.0 & -2.480 & 0.056 & & Decreasing \\
\hline & Summer & 22.111 & 31.4 & 0.704 & 0.513 & & Increasing \\
\hline & Autumn & -115.413 & 82.5 & -1.399 & 0.221 & & Decreasing \\
\hline \multirow[t]{4}{*}{ Clostridium perfringens } & winter & -0.782 & 0.8 & -1.004 & 0.362 & 0.05 & Decreasing \\
\hline & Spring & -1.054 & 0.6 & -1.785 & 0.134 & & Decreasing \\
\hline & Summer & -0.313 & 0.3 & -1.020 & 0.355 & & Decreasing \\
\hline & Autumn & -1.022 & 0.2 & -5.291 & 0.003 & & Significantly Decreasing \\
\hline \multirow[t]{4}{*}{ Intestinal enterococci } & winter & -1.464 & 1.5 & -0.979 & 0.353 & 0.05 & Decreasing \\
\hline & Spring & -6.212 & 2.1 & -2.960 & 0.016 & & Significantly Decreasing \\
\hline & Summer & 0.469 & 0.4 & 1.063 & 0.316 & & Increasing \\
\hline & Autumn & -2.163 & 2.1 & -1.021 & 0.334 & & Decreasing \\
\hline \multirow[t]{4}{*}{ Escherichia coli } & winter & -1.420 & 2.3 & -0.627 & 0.544 & 0.05 & Decreasing \\
\hline & Spring & 1.055 & 0.8 & 1.339 & 0.207 & & Increasing \\
\hline & Summer & 0.669 & 0.5 & 1.315 & 0.215 & & Increasing \\
\hline & Autumn & -1.255 & 0.9 & -1.394 & 0.191 & & Decreasing \\
\hline \multirow[t]{4}{*}{ Coliform bacteria } & winter & -20.144 & 12.1 & -1.661 & 0.125 & 0.05 & Decreasing \\
\hline & Spring & -3.731 & 6.9 & -0.536 & 0.603 & & Decreasing \\
\hline & Summer & 3.043 & 5.1 & 0.594 & 0.564 & & Increasing \\
\hline & Autumn & 5.088 & 12.9 & 0.394 & 0.701 & & Increasing \\
\hline
\end{tabular}




\subsection{Extreme Events Analysis}

The application of extreme value theory based on Generalized Extreme Value (GEV) distribution for water quality management through risk analysis, design and operation of west water treatment plant and sewer system was discussed (Thas et al. 1997). Particle counts in raw and treated water were subjected to numerical analysis of GEV followed by a recurrence curve to suggest a threshold value that is crucial for water quality monitoring (Persson and La 2012). In this study, extreme value theory was applied through POT method on the microbial source water quality detaset in order to analyse the risk and optimize water treatment practices.

The application of the POT method with the intention of calculating the probability of incidence of extreme events involves the following three steps: (1) select the threshold $u$ value; (2) fit the GP distribution function to the exceedances over threshold data, and then estimate the shape and scale parameters; and (3) compute the return level of the extreme event using estimated parameters.

\subsubsection{Threshold (u) selection}

Figure 6 shows the sample mean excess plots corresponding to the selected microbial organisms in the raw water. Since, reasonable threshold values are obtained from linearity between mean excess values and excess over thresholds, based on a closer inspection of the plots, we suggest the values: $\mathrm{u}=1800 / \mathrm{mL}$ for HPC, $\mathrm{u}=9 / 100 \mathrm{~mL}$ for C.perfringens, $\mathrm{u}=29 / 100 \mathrm{~mL}$ for intestinal enterococci, $\mathrm{u}=90 / 100 \mathrm{~mL}$ for E.coli, and $\mathrm{u}=330 / 100 \mathrm{~mL}$ for coliform bacteria. These values are located at different sections of the mean excess plots that are roughly linear, leaving respectively $38,62,42,47$, and 70 observations of the tail section for further analysis (Table 7). The other criterion to select the threshold is a threshold stability plot which presents the shape parameter against threshold values and the exceedances with $95 \%$ confidence interval (Fig. 7). As we can see from Fig. 7, a reasonable stable position close to the highest threshold is the position of our threshold values; hence, our threshold values look reasonable.
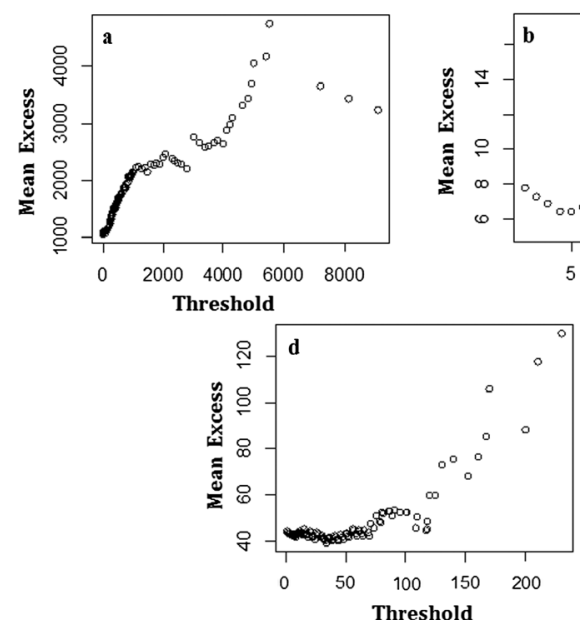
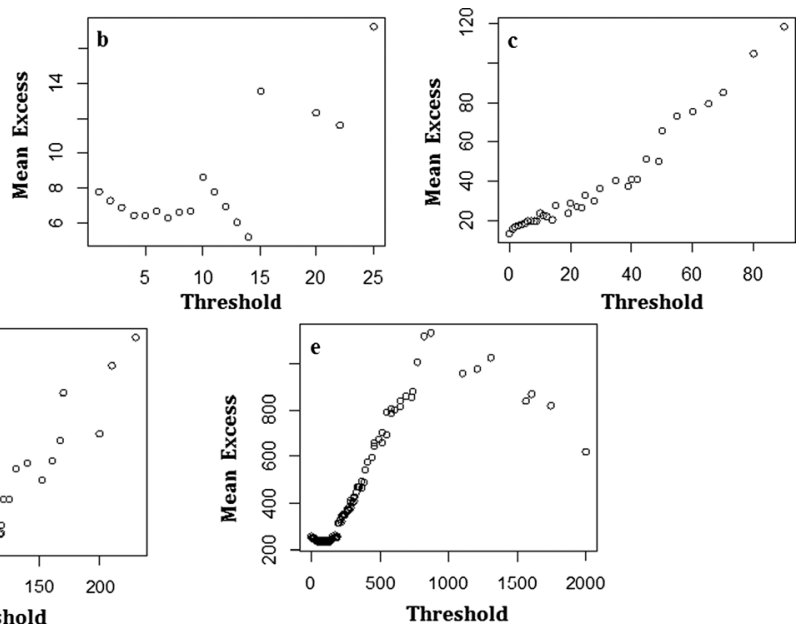

Fig. 6 Mean residual life plot for: a HPC; b Clostridium perfringens; $\mathbf{c}$ Intestinal Enterococci; $\mathbf{d}$ Escherichia coli; e Coliform bacteria 
Table 7 Estimated parameters of GP distribution fit to microbial load detaset to compute extreme load frequency

\begin{tabular}{llllll}
\hline Parameters & HPC & $\begin{array}{l}\text { Clostridium } \\
\text { perfringens }\end{array}$ & $\begin{array}{l}\text { Intestinal } \\
\text { enterococci }\end{array}$ & $\begin{array}{l}\text { Escherichia } \\
\text { coli }\end{array}$ & $\begin{array}{l}\text { Coliform } \\
\text { bacteria }\end{array}$ \\
\hline Total N & 298 & 302 & 456 & 547 & 547 \\
Threshold value $(\mathrm{u})$ & 1800 & 9 & 29 & 90 & 330 \\
N above threshold & 38 & 62 & 42 & 47 & 78 \\
Shape parameter $(\mathrm{k})$ & 0.09 & 0.16 & 0.57 & 0.15 & 0.64 \\
Scale parameter $(\alpha)$ & 2408.3 & 5.9 & 13.8 & 45.3 & 218.7 \\
No. of exceedances per year $(\lambda)$ & 5.4 & 8.9 & 3.5 & 3.9 & 6.5 \\
\hline
\end{tabular}

\subsubsection{Estimation of Parameters and Model Validation}

After determining the threshold values using the exceedances detaset, the GP distribution parameters were estimated using $\mathrm{R}$ statistical software. There are different numerical techniques available for the estimation of the parameters of the extreme value distributions. From the different methods, the Maximum Likelihood (ML) technique tends to be the selected one since it is relatively general and more flexible than other methods (Hosking and Wallis 1987), and was applied in this study.

Table 7 shows the scale $(\alpha)$ and shape $(\mathrm{k})$ parameters with their corresponding threshold value for each indicator microbial organisms in the raw water. The shape parameters have negative value and are close to zero for all microbes, while the scale parameters have a huge variation among the different microbes. The number of exceedances per year $(\lambda)$, which is used to compute the return level, is calculated by dividing the number of observations over the threshold value by the number of years the observations are carried out.

Figure 8 shows the probability plots (a), and Quantile plots (b), for HPC (1), C.perfringens (2), intestinal enterococci (3), E.coli (4), and coliform bacteria (5). The plots are used to test
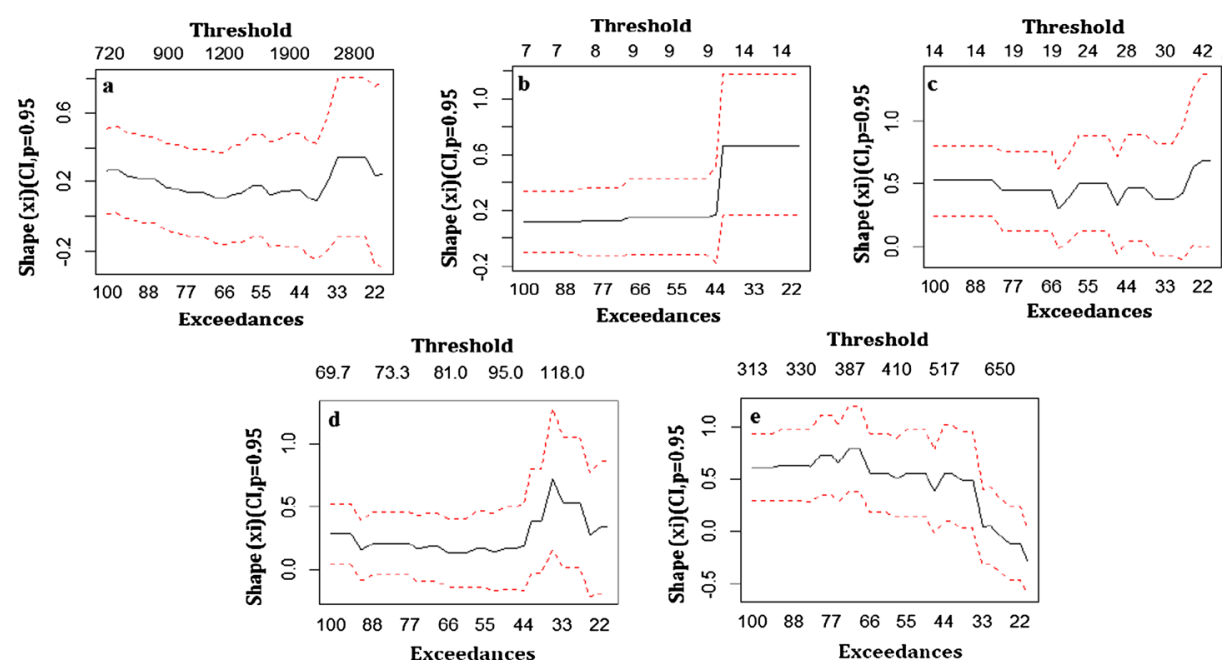

Fig. 7 Threshold stability plots for: a HPC; b Clostridium perfringens; c Intestinal Enterococci; d Escherichia coli; e Coliform bacteria 
whether the exceedances detaset follows the Generalized Pareto Distribution or not. The probability and quantile plots of GP distribution model and microbial load data are close to linear, with relatively slight debate in the case of C.perfringens and intestinal enterococci. We can see that all diagnostic plots show valid results for all microbial load data. Therefore, the model can be used to predict extremes through return levels for different return periods.

\subsubsection{Return level of the extreme event}

Based on the parameter values which are estimated by the maximum likelihood method, and assuming that extreme microbial load data are from stationary processes, return levels are provided in Fig. 9. The return levels gradually increase for higher return periods. From the above results one would expect, for example, HPC loads in the raw water to exceed about $16151 / \mathrm{mL}$ on the average once every 10 years, and about $22739 / \mathrm{mL}$ on the average once every 50 years, or E.coli in the raw water to exceed about $376 / 100 \mathrm{~mL}$ on the average once every 10 years, and about $542 / 100 \mathrm{~mL}$ on the average once every 50 years. The applicability of this result for drinking water treatment plans is that the design of the microbial pathogen barriers should consider these extreme events in order to minimize microbial risk.

\subsection{Practical Implications and Limitations of the Study}

Monitoring of source water microbial load is a common practice in water treatment plants, and long records of microbial concentration data are available. Such datasets may be used in statistical analysis for various purposes. The findings of this study reveal a number of practical applications of value for watershed management, water treatment practices, and risk analysis in relation to microbial source water quality.

Source water microbial load trend analysis may reveal existing trends in the time series that could have a direct association with deterioration or improvement in watershed management practices. Results from such analyses can be valuable as a first evaluation of watershed
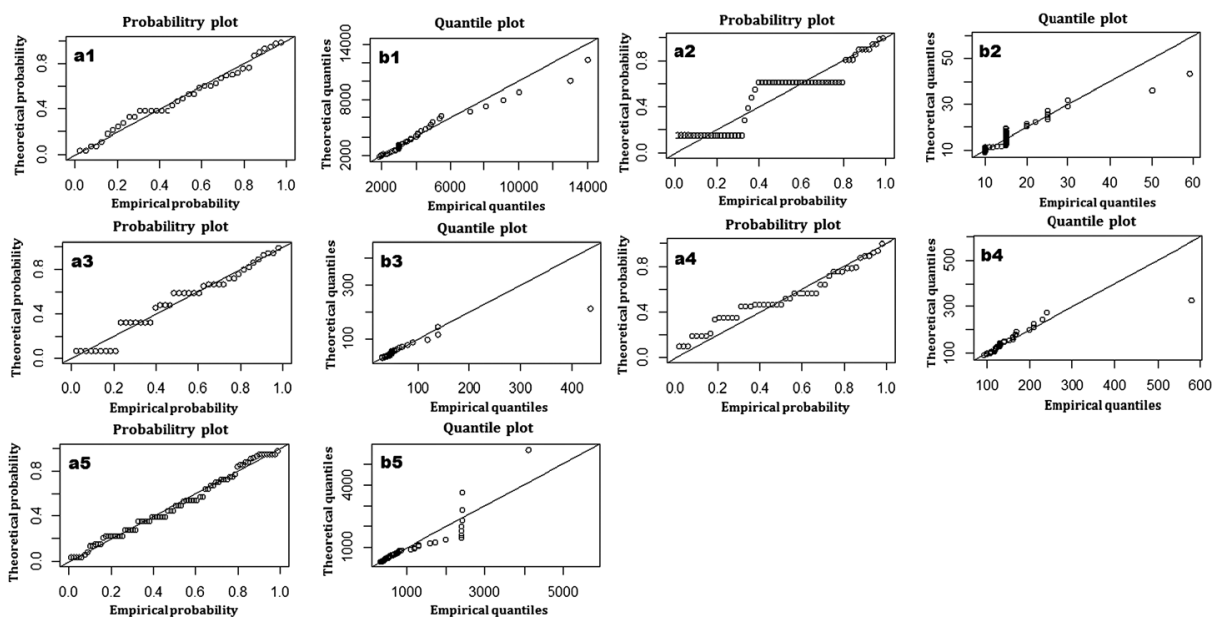

Fig. 8 Non-exceedance probability plots for GP distribution fit to detasets of: (a1) HPC; (a2) Clostridium perfringens; (a3) Intestinal Enterococci; (a4) Escherichia coli; (a5) Coliform bacteria; and non-exceedance quantile plots for GP distribution fit to detasets of: (b1) HPC; (b2) Clostridium perfringens; (b3) Intestinal Enterococci; (b4) Escherichia coli; (b5) Coliform bacteria 


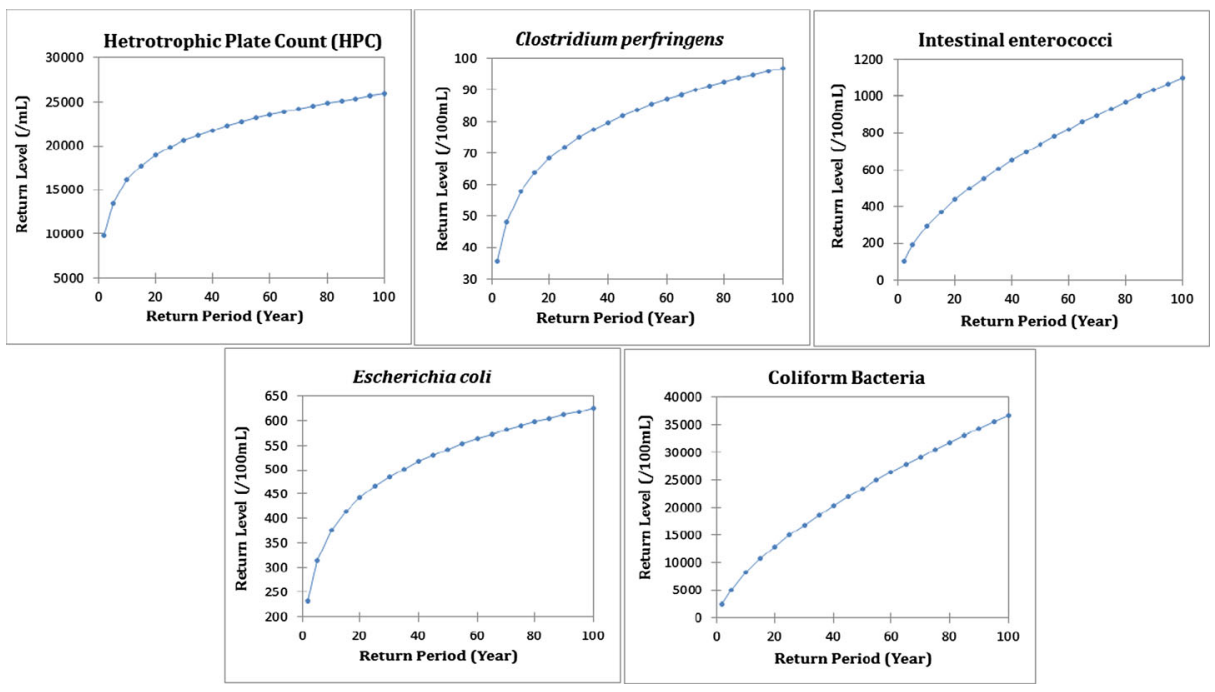

Fig. 9 Return level plots for different indicator microorganisms

management and for recommending further examinations of the causes of any observed trends, as well as monitoring the results of management interventions.

Extreme source water microbial load events at drinking water treatment plants are rare, but important for microbial risk analysis. The quantification of extreme quantiles using extreme value theory assists in determining suitable treatment steps for pathogen removal based on risk assessments. These techniques are regularly used in the areas of storm, flood and high wind events. However, little work has been done for extremes in microbial water quality variables. This study demonstrates the application of extreme value theory on a microbial water quality detaset. Quantitative microbial risk models rely on knowing the probabilities of extreme microbial load events and also include a probabilistic representation of the performance of pathogen treatment barriers. Therefore, integrating extreme event analysis in risk models, may give opportunities for optimization of drinking water treatment with respect to microbial risk.

Even though this study generated important findings in the field of statistical analysis of microbial water quality, a number of caveats need to be noted and we have to acknowledge the limitations. The main limitations are expressed as follows:

- The monitored microbial detaset at the drinking water treatment plant was provided as a working document, and could not be checked for errors. Therefore, any data quality issues such as missing, erroneous, extreme and duplicate values will affect the results.

- There are also limitations associated with changes in laboratory analytical techniques. When the analytical techniques change due to, e.g., technological advancement, this could also be a source of variation in the results.

- Since the temporal resolution of data points are weekly time steps, there will be some limitation associated with capturing variation of microbial load in the river system. 


\section{Summary and Conclusions}

Analytical tools should be developed to properly evaluate catchment management strategies, design appropriate microbial barrier mechanisms in drinking water treatment plants, and monitor water quality improvements or deterioration at different catchment scale. Thus, integrated studies of water quality and statistics are crucial to create analytical tools to support the decision making processes. In this study, statistical principles were applied for trend and extreme value analysis of microbial loads in a drinking water source, in order to demonstrate how the microbial load time series in drinking water treatment plants could be used as a potential source of information for catchment management and pathogen barrier design in the treatment plant.

Monitoring of microbial loads in the raw water is the main task of drinking water treatment plants to determine the current hygienic status of raw water. At the same time there is an opportunity to use microbial load time series for trend analysis in order to know whether watershed management strategies have beneficial effect or not. The analytical results of monthly mean microbial load trend analysis indicate that there is a decreasing trend for all indicator microorganisms except E.coli. Seasonal trend analysis results confirmed a decreasing trend for all indicator microorganisms except E.coli during the spring season and an increasing trend for all pathogens during the summer. Therefore, this study could offer insights and crucial perspective as a case study for policy makers and planners in helping them to evaluate the existing catchment management strategies. Besides, it could assist decision making processes in order to identify priorities of catchment management focal points.

Extreme microbial load events in the raw water were analyzed using the Peak-OverThreshold (POT) method to estimate return levels of five indicator microorganisms corresponding to selected return periods. The Generalized Pareto distribution was implemented to extrapolate raw water microbial load to levels more extreme than those observed. The analytical results indicate that the generalized pareto distribution function seems to provide an adequate fit to the microbial load extreme detaset above a certain threshold value. Diagnostic plots (p-p plots and q-q plots) indicate that the Generalized Pareto distribution is an appropriate model and that the underlying assumptions are reasonable for the data analyzed. In other words, it is possible to apply extreme value theory to obtain reliable prediction of extreme microbial load for drinking water treatment plant based on their own record, so as to explore the risk of extreme microbial load and to propose equivalent mitigation measures.

Complete removal of microbial pathogen from the raw water is one of the main tasks of drinking water treatment plants. In achieving the goal, it needs to build proper pathogen barriers that will provide safe drinking water quality even during extremely high microbial load events of raw water. However, the pathogen load of the raw water varies from day to day in an apparently random way. Thus, the analysis of extreme events could be applied as a tool to help drinking water treatment engineers to deal with the likely occurrence of extreme loads. The significance of calculating the return period of extreme microbial load events is to determine the probability that an extreme pathogen load event will occur, for the purpose of optimal pathogen barrier design and microbial risk analysis.

Acknowledgments The authors wish to thank the Nedre Romerike Vannverk (NRV) drinking water treatment plant, and the project manager Lena Solli Sal, and also the Hydro-informatics section of Norges Vassdrags og Energidirektorat (NVE) for providing the required detaset used in this study. 


\section{References}

Abaurrea J, Asin J, Cebrian AC, Garcia-Vera MA (2011) Trend analysis of water quality series based on regression models with correlated errors. J Hydrol 400(3-4):341-352. doi:10.1016/j.jhydrol.2011.01.049

Antonopoulos VZ, Papamichail DM, Mitsiou KA (2001) Statistical and trend analysis of water quality and quantity data for the Strymon River in Greece. Hydrol Earth Syst Sci 5(4):679-691

Castillo E, Hadi AS (1997) Fitting the generalized Pareto distribution to data. J Am Stat Assoc 92(440):1609-1620

Deoliveira JT (1988) Stochastic-processes of extremes - definitions and statistics. Adv Appl Probab 20(1):7

El-Aroui M-A, Diebolt J (2002) On the use of the peaks over thresholds method for estimating out-of-sample quantiles. Comput Stat Data An 39(4):453-475. doi:10.1016/S0167-9473(01)00087-1

Embrechts P, Klüppelberg C, Mikosch T (1997) Modelling extremal events: for insurance and finance. Springer, Berlin, pp 283-358

Ercelebi SG, Toros H (2009) Extreme value analysis of Istanbul air pollution data. Clean-Soil Air Water 37(2):122-131

Falk M, Guillou A (2008) Peaks-over-threshold stability of multivariate generalized Pareto distributions. J Multivar Anal 99(4):715-734

Freudenthal AM (1976) Extreme value risk analysis in structural design of reactor components. Nucl Eng Des 37(1):179-181

Gilbert RO (1987) Statistical Methods for Environmental Pollution Monitoring. Wiley, New York, pp 204-252

Grizzetti B. BF, Bianchi M., Barkved L., Berge D., Campbell D., Dan Kim N., Gooch G., Lana Renoult N., Nesheim I., Machado M., Manasi S., Rieu-Clarke A., Stålnacke, P. and Tjomsland T. (2007) Managing data in Integrated Water Resources Management projects: the STRIVER case. European Commission Joint Research Center. Institute for Environment and Sustainability. Rural, Water and Ecosystem Resources Unit (JRC-EC). doi:http://kvina.niva.no/striver/Portals/0/documents/STRIVER_D21.pdf

Hadas O, Corradini MG, Peleg M (2004) Statistical analysis of the fluctuating counts of fecal bacteria in the water of Lake Kinneret. Water Res 38(1):79-88. doi:10.1016/j.watres.2003.09.004

Hait JR, Schektman Y (1980) Characterization of principal directions and components in principal components analysis (PCA) - similar components analysis. Biometrics 36(2):368-368

Heffernan JE (2012) An Introduction to Statistical Modeling of Extreme Values. Package 'ismev’. http://cran.rproject.org/web/packages/ismev/ismev.pdf.

Helsel DR, Hirsch RM (2002) Statistical Methods in Water Resources. In: Techniques of Water Resources Investigations, vol Book 4. vol chapter A3. U.S. Geological Survey, p 522

Hirsch RM, Slack JR, Smith RA (1982) Techniques of trend analysis for monthly water-quality data. Water Resour Res 18(1):107-121. doi:10.1029/Wr018i001p00107

Hosking JRM, Wallis JR (1987) Parameter and quantile estimation for the generalized Pareto distribution. Technometrics 29(3):339-349. doi:10.2307/1269343

Huang YL, Batterman S (2003) An extreme value analysis of pollutant concentrations in surface soils due to atmospheric deposition. Hum Ecol Risk Assess 9(7):1729-1746

Iii JP (1975) Statistical inference using extreme order statistics. Ann Stat 3(1):119-131. doi:10.2307/2958083

Jiang YY, Zhuang QL (2011) Extreme value analysis of wildfires in Canadian boreal forest ecosystems. Can J Forest Res 41(9):1836-1851

Kasperski M, Hoxey R (2008) Extreme-value analysis for observed peak pressures on the Silsoe cube. J Wind Eng Ind Aerod 96(6-7):994-1002

Katz RW, Parlange MB, Naveau P (2002) Statistics of extremes in hydrology. Adv Water Resour 25(8-12): 1287-1304

Klugman S (1997) Practical analysis of extreme values. Insur Math Econ 21(1):91-92. doi:10.1016/S01676687(97)00022-X

Konecny F, Nachtnebel HP (1985) Extreme value processes and the evaluation of risk in flood analysis. Appl Math Model 9(1):11-15

Kuchenhoff H, Thamerus M (1996) Extreme value analysis of Munich air pollution data. Environ Ecol Stat 3(2): 127-141

Lang M, Ouarda TBMJ, Bobee B (1999) Towards operational guidelines for over-threshold modeling. J Hydrol 225(3-4):103-117

Leadbetter MR, Rootzen H (1988) Extremal theory for stochastic processes. Ann Probab 16(2):431-478

Li YH, Gao H, Li LY, Wang X (2010) Analysis of the surface water quality status and developing trend of the Yellow River Basin in the early 21st century. Proceedings of the 4th International Yellow River Forum on Ecological Civilization and River Ethics, Vol Ii:113-122

Luo PP, He B, Takara K, Razafindrabe BHN, Nover D, Yamashiki Y (2011) Spatiotemporal trend analysis of recent river water quality conditions in Japan. J Environ Monit 13(10):2819-2829. doi:10.1039/C1em10339c

Mazas F, Hamm L (2010a) The peaks-over-threshold statistical theory for the estimation of extreme sea-states. Part 1: a review of available methods. Houille Blanche 4:96-102 
Mazas F, Hamm L (2010b) The peaks-over-threshold statistical theory for the estimation of extreme sea-states. Part 2: case studies. Houille Blanche 4:103-110

Naess A (1998) Statistical extrapolation of extreme value data based on the peaks over threshold method. J Offshore Mech Arct 120(2):91-96

Persson J, La KM (2012) On selection of threshold values in alarm-systems for drinking water monitoring. VATTEN - J Water Manag Res 1(68):43-51

Reay WG (2009) Water quality within the York river estuary. J Coastal Res: Spec Issue 57:23-39

Ross WH (1987) A peaks-over-threshold analysis of extreme wind speeds. Can J Stat 15(4):328-335

Sen PK (1968) Estimates of the regression coefficient based on Kendall's Tau. J Am Stat Assoc 63(324):13791389. doi: $10.1080 / 01621459.1968 .10480934$

Simiu E, Heckert NA (1996) Extreme wind distribution tails: A "peaks over threshold" approach. J Struct Eng ASCE 122(5):539-547

Thas O, Vanrolleghem P, Kops B, VanVooren L, Ottoy JP (1997) Extreme value statistics: potential benefits in water quality management. Water Sci Technol 36(5):133-140. doi:10.1016/S0273-1223(97)00498-8

Wong TST, Li WK (2010) A threshold approach for peaks-over-threshold modeling using maximum product of spacings. Stat Sini 20(3):1257-1272

XLSTAT (2012) Running a partial least squares (PLS) discriminant analysis with XLSTAT-PLS. http://www.xlstat. com/en/learning-center/tutorials/running-a-partial-least-square-pls-discriminant-analysis-with-xlstat-pls.htm. Accessed May, 272014

Yenilmez F, Keskin F, Aksoy A (2011) Water quality trend analysis in Eymir Lake, Ankara. Phys Chem Earth 36(5-6):135-140. doi:10.1016/j.pce.2010.05.005

Yin X, Hu GH (2009) Trend analysis of surface water quality in Hunan Province. 2009 Proceedings of International Conference on Environmental Science and Information Application Technology, Vol 3,:154 157. doi: Doi 10.1109/Esiat.2009.158

Yu Y-S, Zou S, Whittemore D (1993) Non-parametric trend analysis of water quality data of rivers in Kansas. J Hydrol 150(1):61-80. doi:http://dx.doi.org/10.1016/0022-1694(93)90156-4 